\title{
Focused beam reflectance measurement as a tool for in situ monitoring of the lactose crystallization process
}

\author{
K. Pandalaneni and J. K. Amamcharla ${ }^{1}$ \\ Department of Animal Sciences and Industry/Food Science Institute, Kansas State University, Manhattan 66506
}

\begin{abstract}
Lactose accounts for about 75 and $85 \%$ of the solids in whey and deproteinized whey, respectively. Production of lactose is usually carried out by a process called crystallization. Several factors including rate of cooling, presence of impurities, and mixing speed influence the crystal size characteristics. To optimize the lactose crystallization process parameters to maximize the lactose yield, it is important to monitor the crystallization process. However, efficient in situ tools to implement at concentrations relevant to the dairy industry are lacking. The objective of the present work was to use a focused beam reflectance measurement (FBRM) system for in situ monitoring of lactose crystallization at supersaturated concentrations (wt/ wt) 50,55 , and $60 \%$ at 20 and $30^{\circ} \mathrm{C}$. The FBRM data were compared with Brix readings collected using a refractometer during isothermal crystallization. Chord length distributions obtained from FBRM in the ranges of $<50 \mu \mathrm{m}$ (fine crystals) and 50 to $300 \mu \mathrm{m}$ (coarse crystals) were recorded and evaluated in relation to the extent of crystallization and rate constants deduced from the refractometer measurements. Extent of crystallization and rate constants increased with increasing supersaturation concentration and temperature. The measured fine crystal counts from FBRM increased at higher supersaturated concentration and temperature during isothermal crystallization. On the other hand, coarse counts were observed to increase with decreasing supersaturated concentration and temperature. Square weighted chord length distribution obtained from FBRM showed that as concentration increased, a decrease in chord lengths occurred at $20^{\circ} \mathrm{C}$ and similar observations were made from microscopic images. The robustness of FBRM in understanding isothermal lactose crystallization at various concentrations and temperatures was successfully assessed in the study.
\end{abstract}

Received November 15, 2015.

Accepted March 11, 2016.

${ }^{1}$ Corresponding author: jayendra@ksu.edu
Key words: chord length distribution, lactose crystallization kinetics, lactose concentration

\section{INTRODUCTION}

Lactose is the most abundant carbohydrate present in milk. It is found in concentrations of 4.4 to $5.2 \%$ and is one of the major constituents in infant formulations, dried milk, and whey products. It is also used by the pharmaceutical industry as a filler in tableting and for dry powder inhalers (Lifran et al., 2010). Commercial production of lactose involves concentration of whey or whey permeate or milk permeate by evaporation under vacuum followed by batch crystallization (Zisu et al., 2014). As the temperature of supersaturated mixture is gradually reduced, the degree of supersaturation increases, leading to crystallization of lactose as tomahawk-shaped crystals. Crystal size distribution (CSD) and total lactose yield are the 2 most important measures in monitoring the industrial crystallization of lactose. Crystallization of lactose is influenced by presence of denatured protein, $\mathrm{pH}$ (Modler and Lefkovitch, 1986), degree of supersaturation, presence of impurities (Garnier et al., 2002), agitator speed (Dhumal et al., 2008; Agrawal et al., 2011), and rate of cooling (McLeod et al., 2011; Wong et al., 2012).

Lactose crystallization is a technological operation which starts with nucleation, followed by crystal growth. Nucleation occurs as primary and secondary, where primary nucleation spontaneously occurs within the cooled supersaturated solution. On the other hand, secondary nucleation occurs from crystals already present in the solution (McLeod et al., 2011). The nucleation, crystal size, and lactose yield depend on the crystallizing conditions such as crystallizer design, degree of supersaturation, and rate of cooling, which emphasizes the need to understand the effect of these parameters on crystallization (Raghavan et al., 2001).

The first step in controlling lactose crystallization is to use cost-effective monitoring technologies to follow the process. Several reports have been published on the use of various technologies to monitor lactose crystallization. Amamcharla et al. (2012) used a commercial ultrasound spectrometer in pulse-echo mode 
for in situ monitoring of the isothermal lactose crystallization process and observed an increase in ultrasound attenuation during nucleation and crystal growth. Also, Yucel and Coupland (2011) used ultrasound spectroscopy to study crystallization of lactose in gelatin gels by comparing ultrasound data to turbidity measurements. Mimouni et al. (2005) monitored kinetics of lactose crystallization by using laser light scattering technique and compared with traditional refractometry. Kadam et al. (2010) studied solute concentration measurements by comparing attenuated total reflectance Fourier transform infrared and Fourier transform near infrared spectroscopy for batch crystallization of lactose and concluded that attenuated total reflectance Fourier transform infrared was more reliable because of less fouling of the probe. Arellano et al. (2004) compared refractive index measurements to digital video polarized light microscopy technique to monitor lactose crystallization. Digital imaging was found to be a useful technique to identify induction time but not sensitive enough to monitor crystal growth due to overlapping of crystals. Most of these techniques were carried out in a laboratory scale setup and require extensive scale-up experiments to implement at an industrial scale crystallization process. The dairy industry is still heavily dependent on traditional refractometer technique to follow the lactose crystallization process. However, crystal size characteristics cannot be obtained from refractometer data.
Concentration is a time-dependent phenomenon in lactose crystallization, and monitoring the crystallization step with noninvasive and online methods is essential in current manufacturing practices to meet the required CSD. Focused beam reflectance measurement (FBRM) is a versatile technique for in situ monitoring of chord length distribution (CLD) and rate of change in crystal size. Figure 1 shows the working principle of FBRM, which is extensively reviewed by Huang et al. (2010). Ndoye and Alvarez (2015) successfully used FBRM technique to find significant difference in recrystallization rates in stored ice creams with different stabilizers. Fang et al. (2010) used FBRM to characterize dissolution behavior of milk protein concentrates at different water temperatures. More importantly, Kail et al. $(2008,2009)$ presented a method to analyze dynamic processes such as crystallization and granulation using FBRM. They validated the developed models using $\alpha$-lactose monohydrate as a case study. However, the lactose concentration used the study was around $38.7 \%$ (wt/wt), which was lower than the concentrations generally used in crystallization of lactose in the dairy industry. Generally, the lactose crystallization process employed in the dairy industry involves concentration of whey in the range of 55 to $65 \%$ TS (Bund and Pandit, 2007). Keeping this in view, the objective of the present study was to evaluate the effectiveness of FBRM at lactose concentrations relevant to the industrial scale crystallization of lactose.
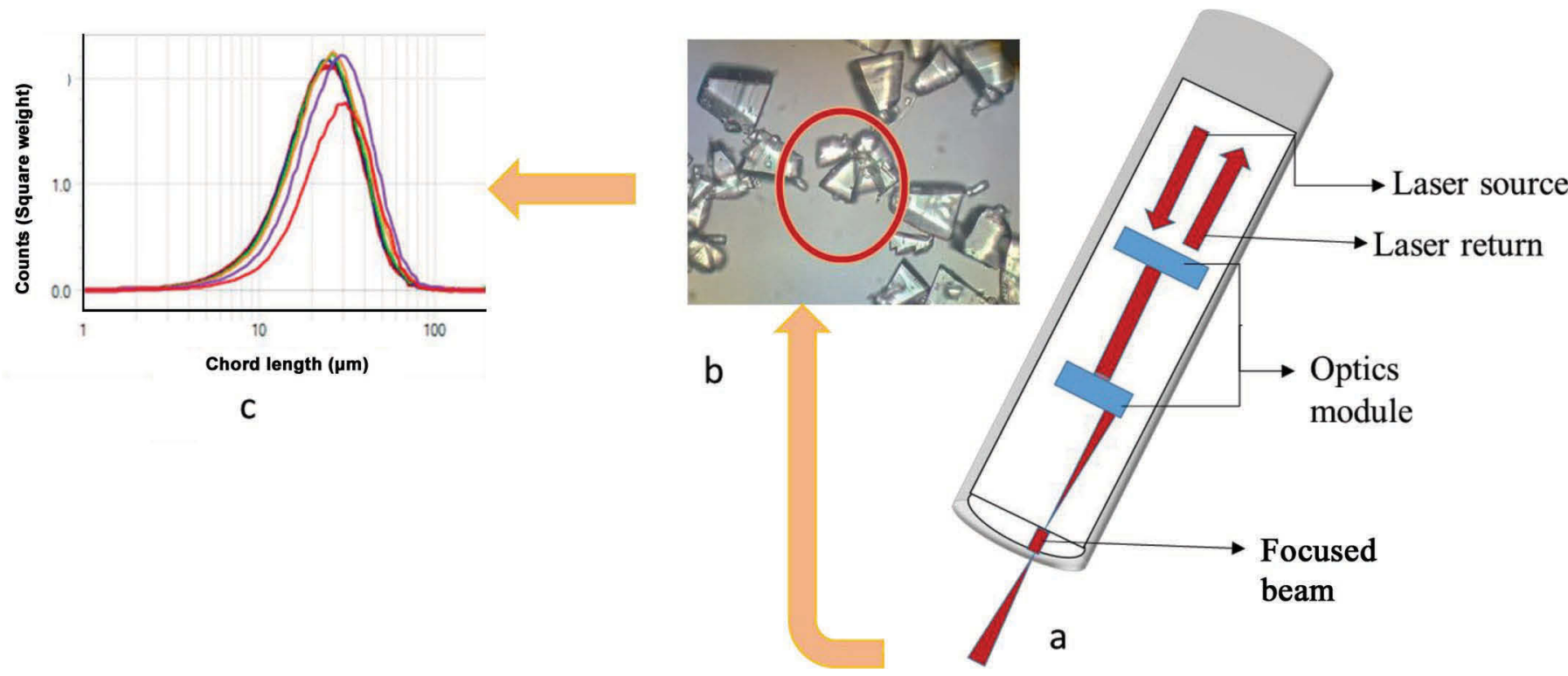

Figure 1. Working principle of focused beam reflectance measurement (FBRM). (a) FBRM probe design, (b) detection of particles by probe using a laser moving at a constant velocity, and (c) chord length distribution graph obtained from crystal distribution. Color version available online. 


\section{MATERIALS AND METHODS}

\section{Experimental Design}

For the purpose of generating wide differences in the lactose crystallization process, a $2 \times 3$ factorial design was used in the study, with temperature and lactose concentration as independent variables. Three levels of lactose concentrations $(50,55$, and $60 \% \mathrm{wt} / \mathrm{wt})$ and 2 levels of temperature $\left(20\right.$ and $\left.30^{\circ} \mathrm{C}\right)$ were incorporated into the experimental design. Isothermal lactose crystallization experiments were conducted in duplicate as per the experimental design.

\section{Preparation of Supersaturated Lactose Solutions}

Lactose solutions of desired concentration were prepared using $99.7 \%$ pure $\alpha$-lactose (Davisco Foods International Inc., Le Seuer, MN). Desired concentrations of lactose (wt/wt) were obtained by dissolving 250,275 , and $300 \mathrm{~g}$ of lactose in 250,225 , and $200 \mathrm{~g}$ of distilled water to prepare $50 \%$ (100 g of lactose/100 g of water), $55 \%$ (122.2 g of lactose/100 g of water), and $60 \%$ (150 g of lactose/100 g of water) supersaturated solutions, respectively. Supersaturated lactose solutions were prepared as described by Mimouni et al. (2005) with few modifications. The lactose and water mixture was heated on a hot plate to $87 \pm 3{ }^{\circ} \mathrm{C}$ under continuous stirring to dissolve all the crystals. A lid was placed on the beaker to avoid moisture loss during heating. After ensuring the dissolution of all the crystals, the supersaturated lactose solution was cooled to the desired experimental temperature $\left(20\right.$ or $\left.30^{\circ} \mathrm{C}\right)$ in a temperature-controlled water bath without agitation for $90 \mathrm{~min}$. Supersaturated lactose solution devoid of any lactose crystals was then carefully transferred to a clean $600-\mathrm{mL}$ batch crystallizer to carry out the isothermal crystallization of lactose.

\section{Isothermal Crystallization of Lactose}

Isothermal lactose crystallization was carried out in a purpose-built batch crystallizer (Figure 2) specially designed for this work. The FBRM probe (Particle Track E25, Mettler-Toledo AutoChem Inc., Columbus, OH) was kept immersed in a batch crystallizer throughout the experiment for in situ monitoring of the crystallization process. The batch crystallizer was placed in a temperature-controlled water bath (Isotemp 202, Fisher Scientific, Waltham, MA) that was maintained at 20 or $30^{\circ} \mathrm{C}$. An overhead stirrer with a 4-bladed propeller (Caframo, Georgian Bluffs, Ontario, Canada) was placed in the batch crystallizer to facilitate stirring. As shown in Figure 2, the propeller was maintained at 2.5 $\mathrm{cm}$ above the bottom of the beaker containing the supersaturated solution. The FBRM probe was mounted at a height of $5 \mathrm{~cm}$ from the bottom of the crystallizer. As suggested by Barrett and Glennon (1999), the FBRM probe was mounted at an angle of $30 \pm 5^{\circ}$ to the vertical axis to improve the efficiency of the probe.

\section{Determination of Extent of Crystallization and Rate Constant}

During crystallization, approximately $1 \mathrm{~mL}$ of the crystal suspension was collected from the crystallizer using a dropper to measure the refractive index of the suspension. The refractive index, expressed in terms of ${ }^{\circ}$ Brix, of lactose solution was measured using a digital refractometer (Reichert Technologies, Depew, NY). A previously generated calibration curve was used to convert the ${ }^{\circ}$ Brix readings to the actual lactose concentration in solution. The refractometer readings were subsequently used to calculate the mass of crystals and extent of crystallization at any time $t$ during isothermal crystallization process. Mass of crystals at any time $t$ was calculated from the initial lactose concentration $\mathrm{C}(0)$ and lactose concentration $\mathrm{C}(t)$ at time $t$ using equation [1]. Water was assumed to represent $5 \%$ of the total mass of lactose crystal (Mimouni et al., 2005).

$$
M_{\mathrm{Crystal}}(t)=M_{\mathrm{H} 2 \mathrm{O}}(0) \cdot \frac{\mathrm{C}(0)-\mathrm{C}(t)}{95-0.05 \cdot \mathrm{C}(t)},
$$

where $M_{\text {Crystal }}(t)$ is mass of crystals at a given time $t$, $M_{\mathrm{H} 2 \mathrm{O}}(0)$ represents $5 \%$ of the total mass of lactose crystal, $\mathrm{C}(0)$ is initial concentration, and $\mathrm{C}(t)$ is concentration at time $t$.

The extent of crystallization at time $t$ was calculated using equation [2] from the mass of crystals at time $t$ obtained from equation [1] and saturation concentration of lactose at temperature 20 and $30^{\circ} \mathrm{C}$ (Mimouni et al., 2005).

$$
\% Y(t)=\frac{M_{\mathrm{Crystal}}(t)}{M_{\mathrm{Crystal}}(t \rightarrow \infty)} \times 100,
$$

where $Y(t)$ is the percent extent of crystallization at time $t, M_{\text {Crystal }}(t)$ is the mass of crystals obtained from equation [1], and $M_{\text {Crystal }}(t \rightarrow \infty)$ is the mass of crystals at lactose solubility at experimental temperature.

From the concentration difference $\Delta \mathrm{C}$, plotted against time $t$, it was observed that the curve shows best the first-order decay fit. The rate constant can be deduced from plotting equation [3], the first-order 
decay equation, where $\left[A_{0}\right]$ is the initial concentration of lactose solution before crystallization and $k$ is the rate constant. $[A]$ is the concentration difference $\Delta \mathrm{C}$, at a given time $t$, where $\Delta \mathrm{C}=\mathrm{C}(t)-\mathrm{C}(t \rightarrow \infty)$, with $\mathrm{C}(t \rightarrow \infty)$ as lactose solubility value at the temperature of interest.

$$
\ln \left(\frac{[A]}{\left[A_{0}\right]}\right)=-k t .
$$

\section{Crystallization Monitoring Using FBRM}

Before the start of each experiment, the FBRM probe was cleaned thoroughly with distilled water to avoid any interference from unwanted particles, as suggested by the manufacturer. The data from the FBRM probe were acquired using a computer through iC FBRM software (version 4.3.391, Mettler-Toledo AutoChem Inc., Columbia, MD). For simplicity, crystals sizes of lactose were acquired at every $3 \mathrm{~min}$ for the first 60 min and thereafter every $30 \mathrm{~min}$ for $570 \mathrm{~min}$ from pool of collected FBRM data. Three categories of crystal chord length ranges, $<50 \mu \mathrm{m}, 50$ to $300 \mu \mathrm{m}$, and 300 to $2,000 \mu \mathrm{m}$, were monitored and were designated as fine, coarse, and large crystals, respectively.
Chord Length Distribution of Lactose Crystals. The CLD were obtained from FBRM over different time periods of interest. Square weight function was applied to CLD to emphasize on a particular crystal size range. For example, having no weight emphasizes the fine crystals, whereas square weight emphasizes the coarse crystals (Huang et al., 2010). Square weight distribution was applied to CLD in our study to compensate for fine chord lengths of crystals that outweigh coarse chord lengths during crystallization. Distributions at 120 and 600 min were taken representing initial crystallization and toward the end, respectively. Autoscaled percent of crystals was taken on the $y$-axis and chord lengths $(\mu \mathrm{m})$ were taken on the $\mathrm{x}$-axis for easy comparison of chord length shift of crystals irrespective of crystal counts.

\section{Microscopic Examination of Lactose Crystals}

Crystal suspension of approximately $0.2 \mathrm{~mL}$ was collected at 120 and 600 min on a clean glass slide, and an image was acquired immediately with $10 \times$ magnification. Microscopic images of lactose crystals were obtained using a compound microscope (American Optical, Depew, NY) connected to a digital camera (Ken-a-vision, Kansas City, MO).

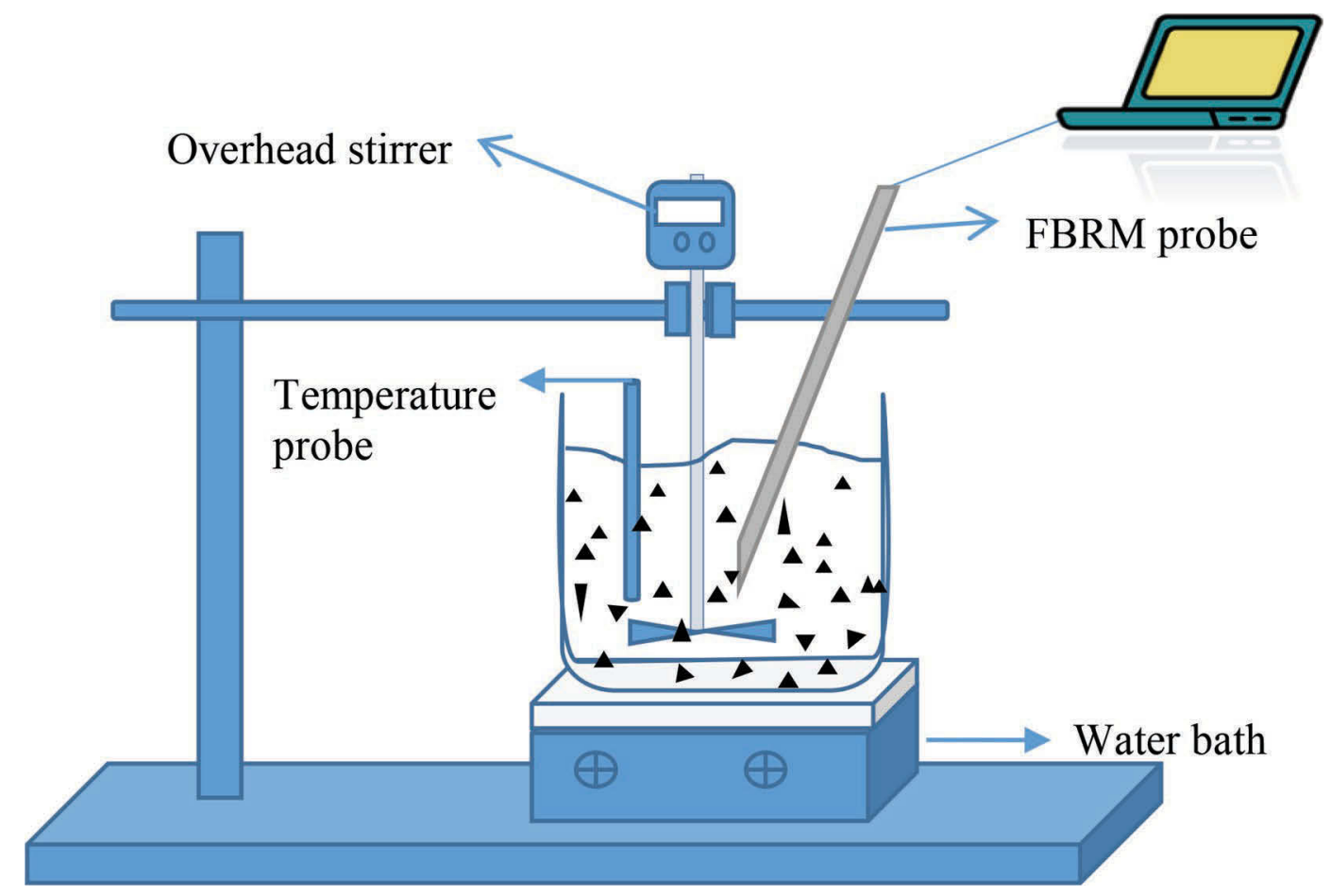

Figure 2. Experimental setup used for monitoring isothermal lactose crystallization using focused beam reflectance measurement (FBRM). Color version available online. 


\section{RESULTS AND DISCUSSION}

\section{Extent of Crystallization and Rate Constant from Refractometry}

The average initial lactose concentrations were found to be $49.05,54.36$, and $59.09 \%$ (wt/wt) for intended 50,55 , and $60 \%$ (wt/wt) lactose solutions. The extent of crystallization was determined during the isothermal crystallization of lactose for 50,55 , and $60 \%$ concentrations at 20 and $30^{\circ} \mathrm{C}$ as plotted in Figure 3. From Figure 3 , it was observed that the extent of crystallization was higher at $30^{\circ} \mathrm{C}$ than at $20^{\circ} \mathrm{C}$ for all concentrations of lactose. A maximum extent of crystallization was observed for $60 \%$ supersaturated solution followed by 55 and $50 \%$ lactose concentrations at $30^{\circ} \mathrm{C}$. The extent of crystallization at $20^{\circ} \mathrm{C}$ also followed a similar trend. At $30^{\circ} \mathrm{C}$, the time required to reach $90 \%$ extent of crystallization was found to be 300, 360, and 420 min for 60,55 , and $50 \%$ solutions, respectively. On the other hand, the extent of crystallization at $20^{\circ} \mathrm{C}$ did not reach $90 \%$ even after $630 \mathrm{~min}$ for all the lactose concentrations studied. The extent of crystallization at $30^{\circ} \mathrm{C}$ was calculated to be 93,95 , and $96 \%$ for 50,55 , and $60 \%$ solutions, respectively. The extent of crystallization at $20^{\circ} \mathrm{C}$ was calculated to be 80,83 , and $86 \%$ for 50,55 , and $60 \%$ solutions, respectively. At a given temperature, the extent of crystallization increased as the supersaturation concentration increased, which is the driving force for the crystallization.
Rate constants for the isothermal crystallization of lactose at 20 and $30^{\circ} \mathrm{C}$ were calculated using equation [3]. For the calculation purposes, it was assumed that the rate of mutarotation proceeded at a higher rate than crystallization of $\alpha$-lactose. This assumption was based on the fact that mutarotation is not a limiting factor during unseeded crystallization of lactose (Raghavan et al., 2001). Calculated average overall rate constants at $20^{\circ} \mathrm{C}$ were $2.7 \times 10^{-3}, 2.8 \times 10^{-3}$, and $2.8 \times 10^{-3}$ $\min ^{-1}$ for 50,55 , and $60 \%$ concentrations, respectively. On the other hand, the average overall rate constants of crystallization at $30^{\circ} \mathrm{C}$ were $4.3 \times 10^{-3}, 4.9 \times 10^{-3}$, and $5.4 \times 10^{-3} \mathrm{~min}^{-1}$ for 50,55 , and $60 \%$ concentrations, respectively. Previous studies on lactose crystallization kinetics available in literature were studied at much lower lactose concentrations than supersaturation concentrations studied in this research. Mimouni et al. (2005) obtained a mean rate constant of $8.1 \times 10^{-3}$ $\min ^{-1}$ during isothermal crystallization of lactose at $30^{\circ} \mathrm{C}$ from an initial lactose concentration of $41.1 \%$ (wt/wt). Arellano et al. (2004) studied isothermal crystallization of lactose at concentrations 27.1, 30.8, and $37.5 \%$ (wt/wt) at $20^{\circ} \mathrm{C}$ and observed growth rates of $2.1,4.1$, and $8.8 \mu \mathrm{m} / \mathrm{h}$, respectively. Similarly, average growth rates of $7.1,9.8$, and $25.8 \mu \mathrm{m} / \mathrm{h}$ were obtained for lactose concentrations $33.3,37.5$, and $44.6 \%$ (wt/wt) at $30^{\circ} \mathrm{C}$. From the results presented by Arellano et al. (2004), it can be seen that single lactose crystal growth rates increased as the temperature increased from 20 to $30^{\circ} \mathrm{C}$ as observed by digital video microscopy technique.

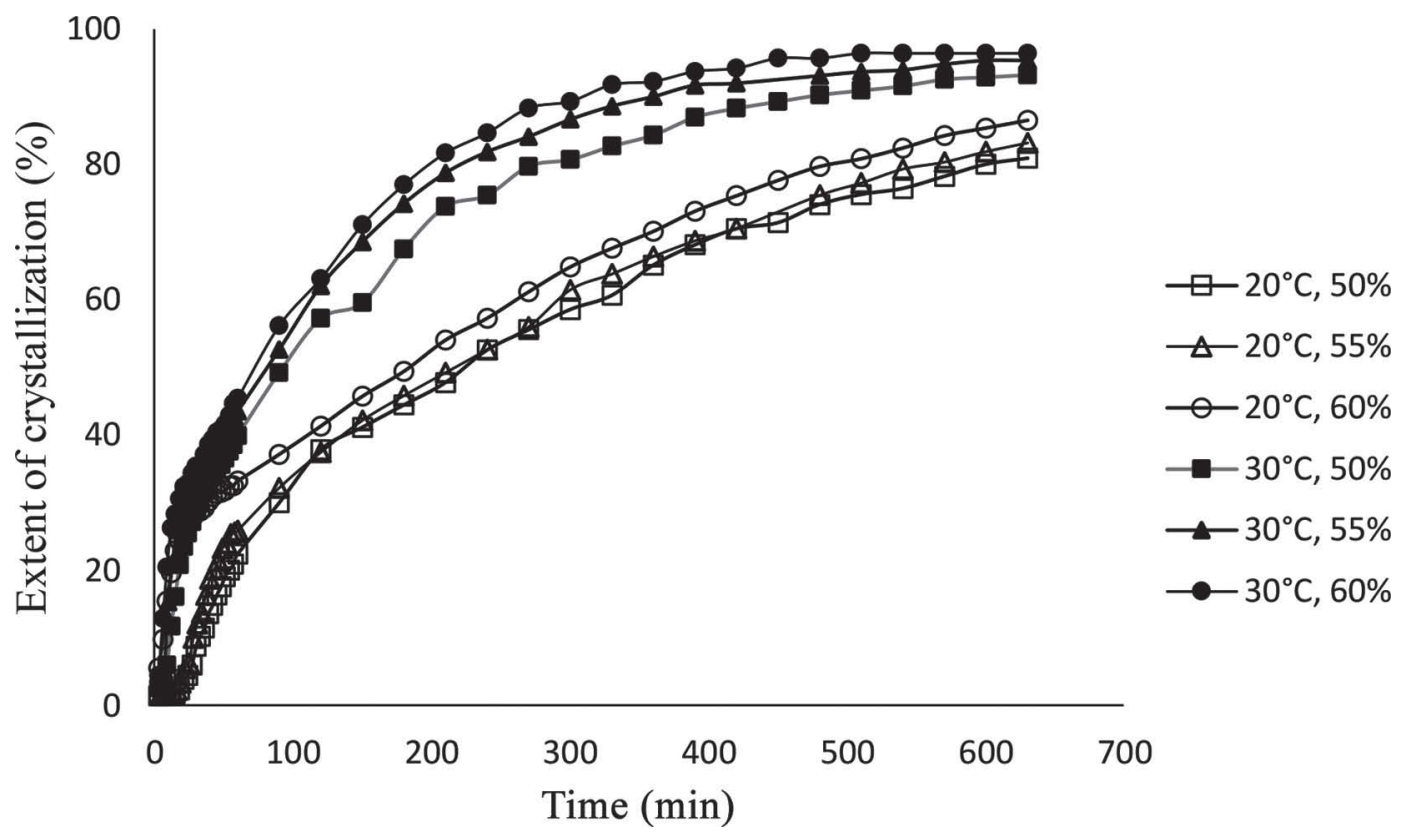

Figure 3. Extent of crystallization obtained during isothermal crystallization of lactose for lactose concentrations 50 , 55 , and $60 \%$ (wt/wt) at 20 and $30^{\circ} \mathrm{C}$. 
In addition, Jelen and Coulter (1973) reported that an increase in crystallization temperature promoted nucleation rates and mass transfer rates of lactose during isothermal crystallization of lactose. The present study also found a higher crystallization rate constant at $30^{\circ} \mathrm{C}$ than at $20^{\circ} \mathrm{C}$ at a given supersaturation concentration.

Overall, refractometry was found to be a useful technique to calculate degree of crystallization at any point during lactose crystallization. In addition, the technique can be implemented easily at any commercial batch crystallizer regardless of crystallizer design. However, refractometer readings do not provide information on CSD. Refractometry is a traditional technique but insensitive to more specific information such as crystal counts and CLD.

\section{Evaluation of FBRM Data}

Fine crystals in this study represented primary and secondary nucleation in terms of crystal chord lengths less than $50 \mu \mathrm{m}$ formed during isothermal lactose crystallization. The ability of FBRM to measure the particles as small as $0.5 \mu \mathrm{m}$ makes it a sensitive tool to monitor fine crystal counts. Counts of fine and coarse crystals $(50-300 \mu \mathrm{m})$ obtained from the FBRM during the isothermal crystallization of lactose at experimental temperatures and concentrations against time were plotted in Figures 4 and 5, respectively. Fine crystal counts obtained for 50,55 , and $60 \%$ concentrations at $30^{\circ} \mathrm{C}$ can be explained in 3 phases: rapid, gradual, and plateaued phase. These were divided based on the increase in fine crystal counts at $30^{\circ} \mathrm{C}$ over $630 \mathrm{~min}$ of crystallization. Rapid increase in the fine crystal counts for first $100 \mathrm{~min}$ of lactose crystallization at $30^{\circ} \mathrm{C}$ was observed at all concentrations and can be attributed to primary nucleation. A gradual increase in the number of fine crystal counts in the later phase was influenced by secondary nucleation and disintegration of lactose crystals. The gradual increase in fine crystal counts can be explained by a reduction in primary nucleation and disintegration of coarse crystals. The disintegration of lactose crystals was caused by attrition and collisions of lactose crystals with other crystals, with the crystallizer walls, and also with propeller used for mixing. It was also noted that the possibility of secondary nucleation increased as counts of lactose crystals increased, which could be observed from fine crystal counts at $30^{\circ} \mathrm{C}$ (Figure 4). Breakage of coarse crystals at concentrations 55 and $60 \%$ can be observed from Figure 5 as fluctuations in the coarse crystal counts staring around $300 \mathrm{~min}$. The coarse crystal counts obtained at 55 and $60 \%$ were eventually lower than the coarse crystal counts observed for $50 \%$ lactose concentration.
The third phase was the plateaued phase, where increase in fine crystal counts plateaued after $300 \mathrm{~min}$. A similar observation was made from extent of crystallization of all 3 concentrations at $30^{\circ} \mathrm{C}$ (Figure 3 ). The minimum increase in the number of fine crystals after 300 min when compared with phase 1 and phase 2 can be explained as a decrease in the driving force of crystallization. Fine crystals formed in the earlier 2 phases restricted the further growth of fine crystals.

Fine and coarse crystal counts at $20^{\circ} \mathrm{C}$ for supersaturation concentrations, 50, 55, and $60 \%$ were also plotted in Figures 4 and 5, respectively. Unlike the fine crystal counts at $30^{\circ} \mathrm{C}$, there was a continuous increase in fine crystal counts at $20^{\circ} \mathrm{C}$ because supersaturation driving force was effective in causing continuous nucleation. However, supersaturation concentration had a similar effect on fine counts at both 20 and $30^{\circ} \mathrm{C}$ : the higher the concentration, the greater the final fine crystal counts. A continuous increase occurred in coarse crystal counts for $50 \%$ concentration at $20^{\circ} \mathrm{C}$, whereas 55 and $60 \%$ concentrations exhibited slow increase in coarse crystal counts, which later decreased after 300 min. The continuous increase in coarse crystal counts of $50 \%$ at $20^{\circ} \mathrm{C}$ was due to having a fewer number of crystals in the total volume of solution, where growth of lactose crystals was not restricted. In the case of 55 and $60 \%$ of the concentrations at $20^{\circ} \mathrm{C}$, fluctuations in the coarse crystal counts after 300 min indicate the breakage of lactose crystals. The observations indicated that breakage of lactose crystals was mainly due to crystal collision rather than breakage caused by the speed of the impeller. The impeller speed (400 rpm) maintained in this experiment was sufficient to keep crystals in suspension without causing any breakage. As the fine crystal counts increased, crystal density in the suspension increased, causing collisions between lactose crystals and leading to breakage.

The number of coarse crystals increased as the temperature and supersaturation decreased. In other words, isothermal crystallization at $20^{\circ} \mathrm{C}$ for supersaturation concentration of $50 \%$ (wt/wt) favored producing coarse crystals larger than $50 \mu \mathrm{m}$ in this study, whereas fine crystal counts increased as temperature and supersaturation increased. These results suggest that growth of crystals was favorable at low temperatures in isothermal lactose crystallization, whereas high temperature favored nucleation and formation of finer crystals. These results were also in agreement with rate constant observations, where nucleation was high at $30^{\circ} \mathrm{C}$, implying formation of fine crystals was favored at high temperatures in isothermal lactose crystallization. In the present study, an increase in fine crystal counts as observed by FBRM represented nucleation of 


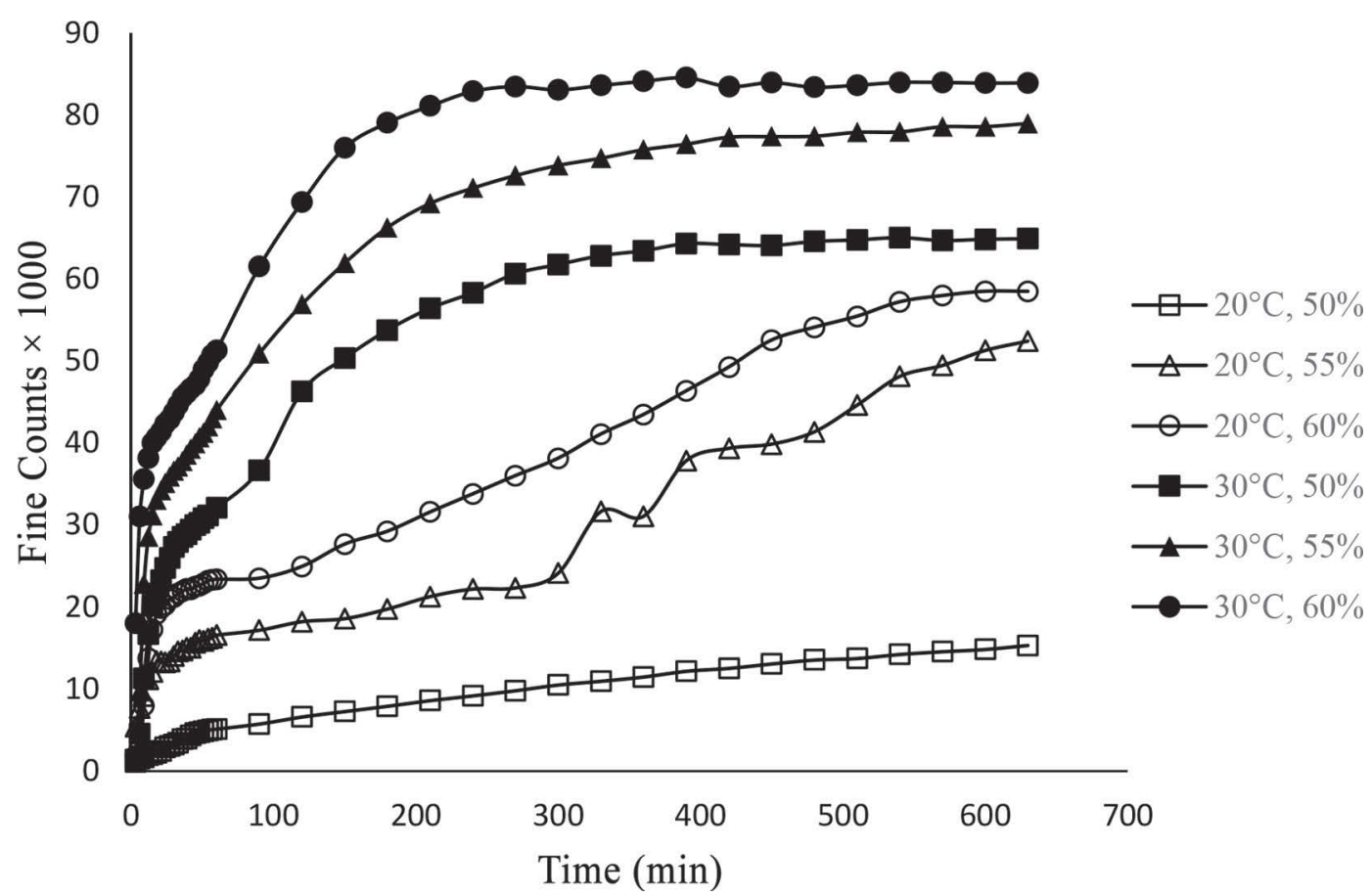

Figure 4. Counts of fine crystals $(<50 \mu \mathrm{m})$ for 50,55 , and $60 \%$ concentrations and at 20 and $30^{\circ} \mathrm{C}$ obtained from focused beam reflectance measurement (FBRM).

lactose. On the other hand, an increase in coarse crystal counts represented lactose crystal growth. As the lactose supersaturation and crystallization temperature increased, nucleation increased as the driving force of lactose crystallization increased.
Focused beam reflectance measurement is capable of following particle chord lengths up to $2,000 \mu \mathrm{m}$. However, counts of larger particles $(300-1,200 \mu \mathrm{m})$ were found to be negligible and were excluded from further analysis.

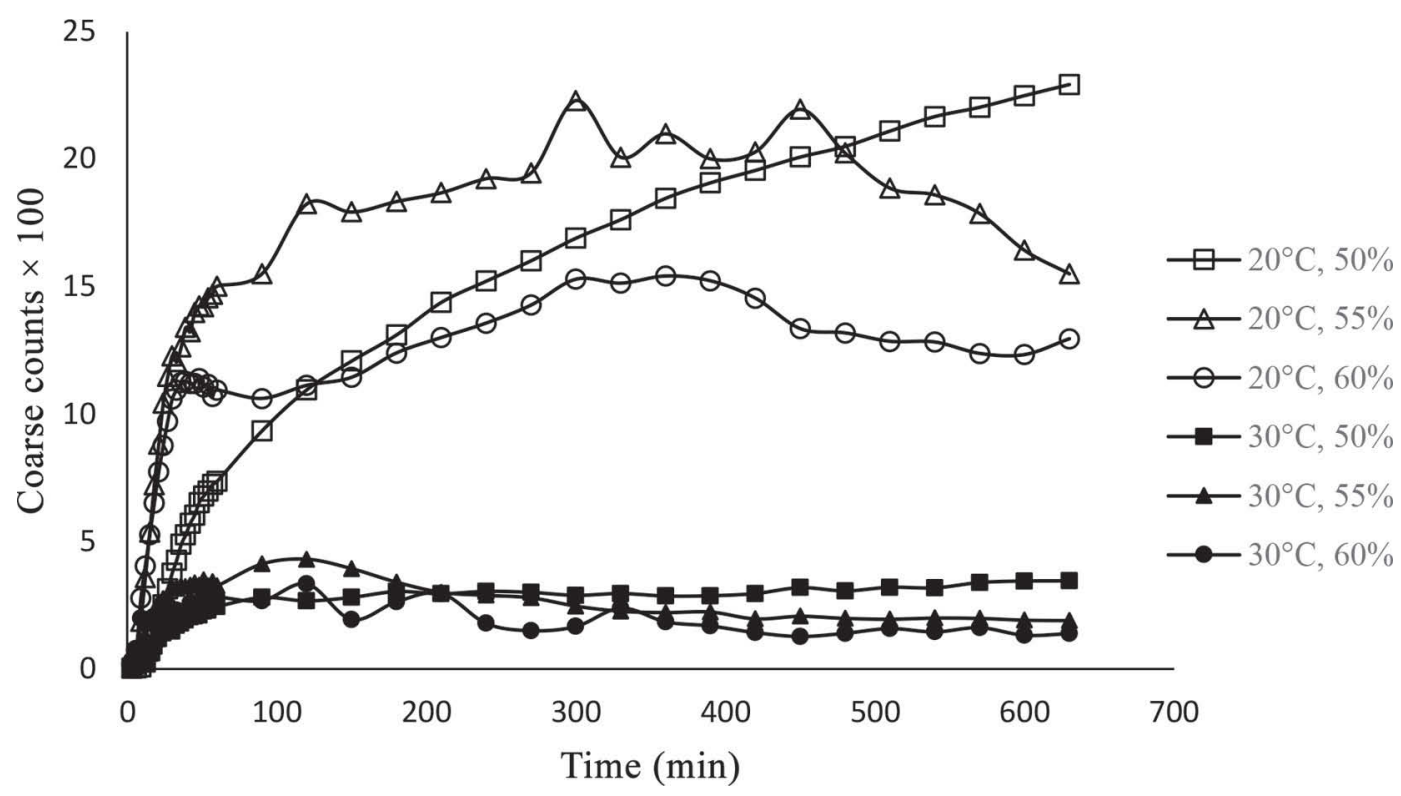

Figure 5. Count of coarse crystals $(50-300 \mu \mathrm{m})$ for 50,55 , and $60 \%$ concentrations and at 20 and $30^{\circ} \mathrm{C}$ obtained from focused beam reflectance measurement (FBRM). 


\section{Evaluation of Chord Length Distribution}

Square weighted CLD obtained from FBRM at 120 and $600 \mathrm{~min}$ of each treatment are shown in Figure 6 . To compare the crystal growth at various supersaturations of lactose, CLD was obtained at 120 and 600 min during isothermal lactose crystallization. It is important to know that the CLD can be obtained at any instant during lactose crystallization using iC FBRM software. However, data at 120 and $600 \mathrm{~min}$ were shown to simplify the data. The CLD of square weighted crystals for $50 \%$ concentration at both 20 and $30^{\circ} \mathrm{C}$ were plotted in Figure 6a. It was evident from CLD that no change occurred in the distribution at 120 and $600 \mathrm{~min}$ at both 20 and $30^{\circ} \mathrm{C}$. However, a difference was found in CLD as the temperature changed. The mean chord lengths of lactose crystals for $50 \%$ concentration at 20 and $30^{\circ} \mathrm{C}$ were $57.99 \mu \mathrm{m}(120 \mathrm{~min})$, $58.10 \mu \mathrm{m}$ (600 min), and $27.25 \mu \mathrm{m}$ (120 min), $27.36 \mu \mathrm{m}$ (600 min), respectively. Mean chord lengths of crystals at $20^{\circ} \mathrm{C}$ were higher than at $30^{\circ} \mathrm{C}$, which implies that growth of crystals was higher at lower temperatures. Similar observations were also deduced from Figures 4 and 5. The CLD of 55 and $60 \%$ lactose concentrations at 20 and $30^{\circ} \mathrm{C}$ was plotted in Figures $6 \mathrm{~b}$ and $6 \mathrm{c}$, respectively. For $55 \%$ concentration at 600 min, mean chord lengths at 20 and $30^{\circ} \mathrm{C}$ were 41.06 and $24.66 \mu \mathrm{m}$, respectively. At $60 \%$ concentration at 600 min, mean chord lengths at 20 and $30^{\circ} \mathrm{C}$ were 39.12 and $23.31 \mu \mathrm{m}$, respectively. At 55 and $60 \%$ concentrations, the CLD shifted toward lower mean chord lengths at 600 min at both the temperatures. As concentration increased, the difference in the mean chord length at 600 min between 20 and $30^{\circ} \mathrm{C}$ decreased.

Though an increase occurred in coarse crystal counts for all the 3 concentrations at $20^{\circ} \mathrm{C}$, a shift in mean chord length to a smaller chord length was explained by an increase in fine crystals counts during isothermal crystallization of lactose. In addition, breakage of the crystals due to crystal-crystal and crystal-crystallizer wall collisions could lead to a decrease in coarse crystals and an increase in fine crystals. As the lactose crystal density (number of crystals per unit volume) increased, the probability of FBRM detecting the particle width rather than particle length was high (Leyssens et al., 2011) and consequently produced smaller mean chord lengths.

The CLD data from FBRM supported by microscopic images of lactose crystals taken at 120 and 600 min at experimental temperatures and 3 supersaturation concentrations are shown in Figure 7. As observed in Figure 7, A1 and A2 at 120 and $600 \mathrm{~min}$, respectively, for $50 \%$ supersaturated concentration at $20^{\circ} \mathrm{C}$, no breakage of crystals was visible. Similarly, in Figure
7, B1 and B2 representing 120 and 600 min observed for $50 \%$ concentration at $30^{\circ} \mathrm{C}$, no visible breakage was observed. Broken crystals were more prominently visible at 55 and $60 \%$ concentrations at $600 \mathrm{~min}$ at both $20^{\circ} \mathrm{C}$ (Figure 7, C2-55\%, E2-60\%) and $30^{\circ} \mathrm{C}$ (Figure 7, D2-55\%, F2-60\%). Broken crystals were observed
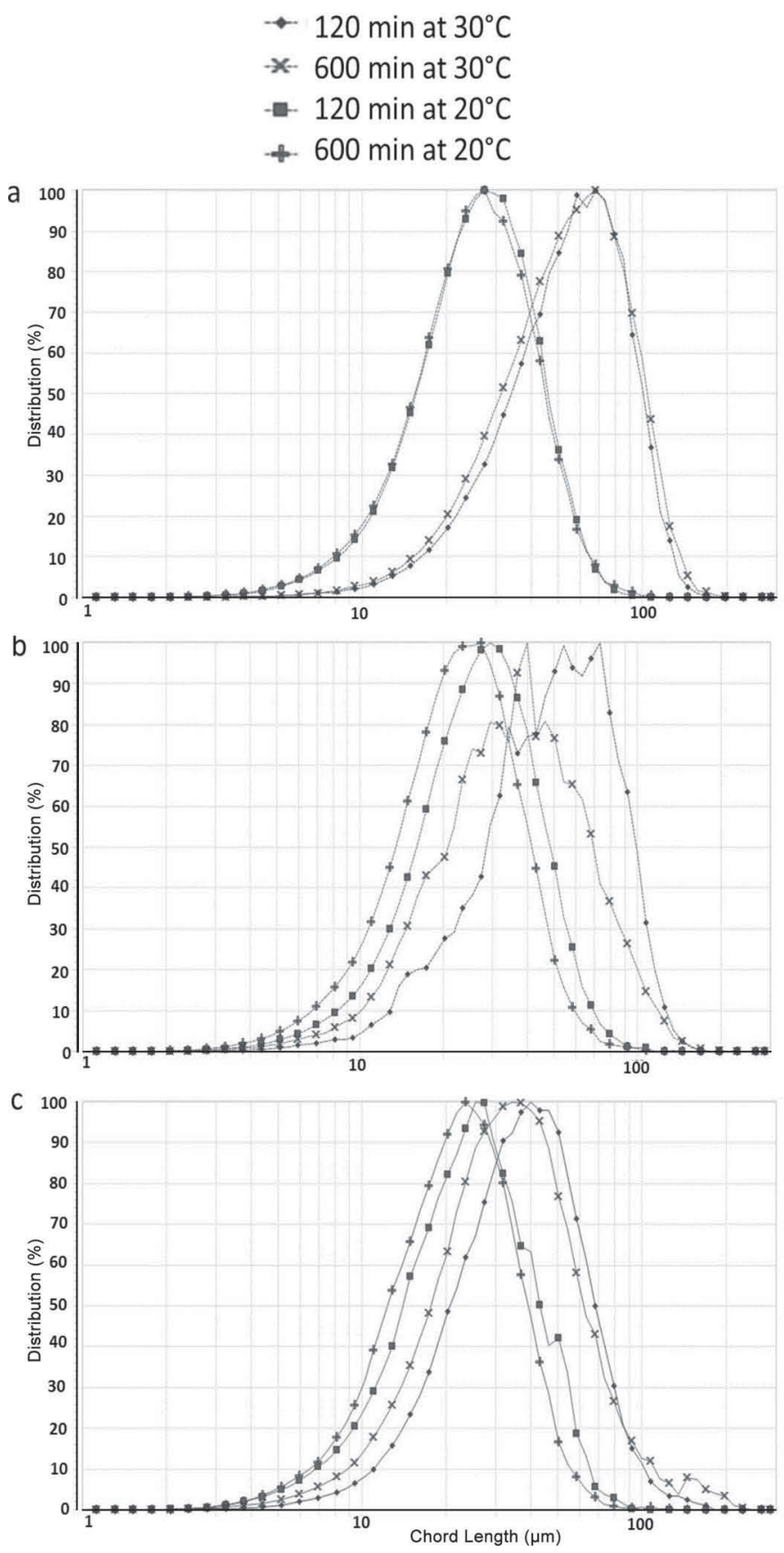

Figure 6. Square weighted, auto-scaled percent chord length distributions of crystals obtained from focused beam reflectance measurement data at 120 and $600 \mathrm{~min}$. (a) $20^{\circ} \mathrm{C}, 50 \% ; 30^{\circ} \mathrm{C}, 50 \%$; (b) $20^{\circ} \mathrm{C}$, $55 \% ; 30^{\circ} \mathrm{C}, 55 \%$; (c) $20^{\circ} \mathrm{C}, 60 \% ; 30^{\circ} \mathrm{C}, 60 \%$. 


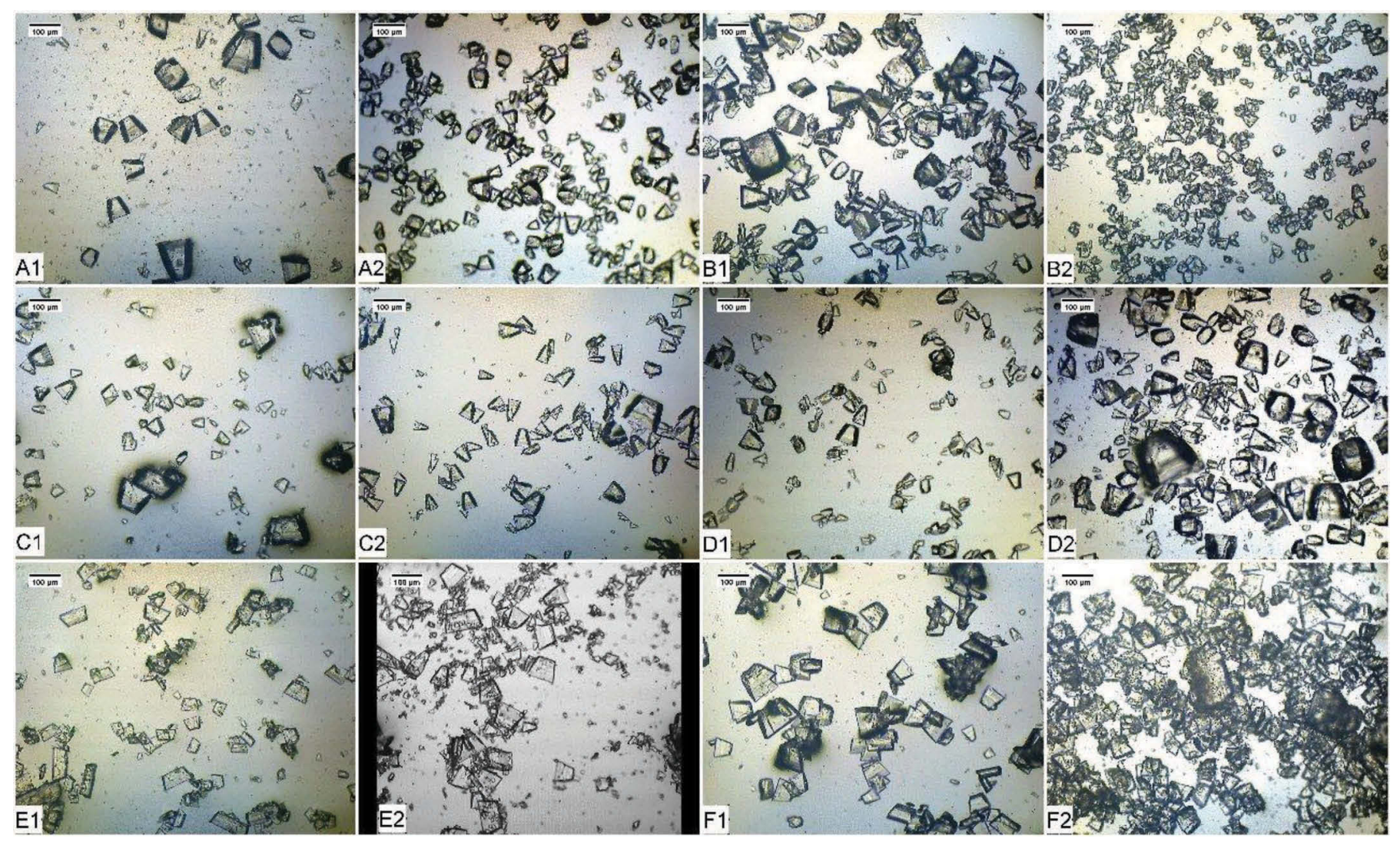

Figure 7. Microscopic images of lactose crystals: (A) $20^{\circ} \mathrm{C}, 50 \%$; (B) $30^{\circ} \mathrm{C}, 50 \%$; (C) $20^{\circ} \mathrm{C}, 55 \%$; (D) $30^{\circ} \mathrm{C}, 55 \%$; (E) $20^{\circ} \mathrm{C}, 60 \%$; (F) $30^{\circ} \mathrm{C}$, $60 \%$ at (1) $120 \mathrm{~min}$ and (2) $600 \mathrm{~min}$ during isothermal crystallization of lactose. Color version available online.

more at $30^{\circ} \mathrm{C}$ crystallization temperature for 55 and $60 \%$ concentrations. These microscopic images support the FBRM data observations made about breakage of crystals contributing to an increase in fine crystal counts.

\section{CONCLUSIONS}

The efficiency of FBRM in studying the lactose crystallization with respect to operation parameters such as concentration and temperature was evaluated. Focused beam reflectance measurement is a powerful tool that can be used to follow nucleation, crystal growth, attrition, and breakage from CLD and crystal size data. Lactose crystallization monitoring using FBRM in this study explained that as the lactose concentration and crystallization temperature increased, possible breakage of crystals increased along with an increase in fine crystal counts. On the other hand, crystal growth increased at $20^{\circ} \mathrm{C}$ rather than at $30^{\circ} \mathrm{C}$. The extent of crystallization obtained from the refractive index data supported the FBRM observations. The results of this study imply that changes in concentration and tem- perature were well understood in terms of crystal size and counts over time using FBRM. The data obtained from FBRM supplement and strengthen the refractive index data. Ideally, coarse crystals were preferred to fine crystals to avoid loss of lactose crystal yield during the postcrystallization process. Overall, the FBRM technique shows potential to be a part of process analytical technology to monitor and control the lactose crystallization process.

\section{ACKNOWLEDGMENTS}

We thank Midwest Dairy Foods Research Center (St. Paul, MN) for their financial support. This is Kansas State Research and Extension contribution number 16088-J.

\section{REFERENCES}

Agrawal, S. G., J. Mcleod, A. H. J. Paterson, and J. R. Jones. 2011 Secondary nucleation studies on lactose: A mechanistic understanding. Pages 677-687 in Chemeca 2011-Engineering a Better World, Sydney, Australia. 
Amamcharla, J. K., L. E. Metzger, and R. Tweedie. 2012. Application of ultrasound spectroscopy to monitor lactose crystallization. J. Dairy Sci. 94(Suppl. 1):653.

Arellano, M. P., J. M. Aguilera, and P. Bouchon. 2004. Development of a digital video-microscopy technique to study lactose crystallisation kinetics in situ. Carbohydr. Res. 339:2721-2730.

Barrett, P., and B. Glennon. 1999. In-line FBRM monitoring of particle size in dilute agitated suspensions. Part. Part. Syst. Charact. 16:207-211.

Bund, R. K., and A. B. Pandit. 2007. Sonocrystallization: Effect on lactose recovery and crystal habit. Ultrason. Sonochem. 14:143152

Dhumal, R. S., S. V. Biradar, A. R. Paradkar, and P. York. 2008 Ultrasound assisted engineering of lactose crystals. Pharm. Res. $25: 2835-2844$.

Fang, Y., C. Selomulya, and X. D. Chen. 2010. Characterization of milk protein concentrate solubility using focused beam reflectance measurement. Dairy Sci. Technol. 90:253-270.

Garnier, S., S. Petit, and G. Coquerel. 2002. Influence of supersaturation and structurally related additives on the crystal growth of

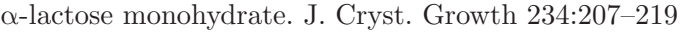

Huang, J., G. Kaul, J. Utz, P. Hernandez, V. Wong, D. Bradley, A. Nagi, and D. O'Grady. 2010. A PAT approach to improve process understanding of high shear wet granulation through in-line particle measurement using FBRM C35. J. Pharm. Sci. 99:3205-3212.

Jelen, P., and S. T. Coulter. 1973. Effects of supersaturation and temperature on the growth of lactose crystals. J. Food Sci. 38:11821185.

Kadam, S. S., E. van der Windt, P. J. Daudey, and H. J. M. Kramer. 2010. A comparative study of ATR-FTIR and FT-NIR spectroscopy for in situ concentration monitoring during batch cooling crystallization processes. Cryst. Growth Des. 10:2629-2640.

Kail, N., H. Briesen, and W. Marquardt. 2008. Analysis of FBRM measurements by means of a 3D optical model. Powder Technol. $185: 211-222$
Kail, N., W. Marquardt, and H. Briesen. 2009. Process analysis by means of focused beam reflectance measurements. Ind. Eng. Chem. Res. 48:2936-2946.

Leyssens, T., C. Baudry, and M. L. Escudero Hernandez. 2011. Optimization of a crystallization by online FBRM analysis of needleshaped crystals. Org. Process Res. Dev. 15:413-426.

Lifran, E. V., R. W. Sleigh, R. L. Johnson, R. J. Steele, J. A. Hourigan, and S. M. Dalziel. 2010. Enhancing purity of lactose via demineralization and alcohol precipitation; infant dairy product; veterinary medicine. Dairy Australia Limited, assignee. US Pat. No. 7754876 B2.

McLeod, J., A. H. J. Paterson, J. R. Jones, and J. E. Bronlund. 2011. Primary nucleation of alpha-lactose monohydrate: The effect of supersaturation and temperature. Int. Dairy J. 21:455-461.

Mimouni, A., P. Schuck, and S. Bouhallab. 2005. Kinetics of lactose crystallization and crystal size as monitored by refractometry and laser light scattering: effect of proteins. Lait 85:253-260.

Modler, H. W., and L. P. Lefkovitch. 1986. Influence of pH, casein, and whey protein denaturation on the composition, crystal size, and yield of lactose from condensed whey. J. Dairy Sci. 69:684-697.

Ndoye, F. T., and G. Alvarez. 2015. Characterization of ice recrystallization in ice cream during storage using the focused beam reflectance measurement. J. Food Eng. 148:24-34.

Raghavan, S. L., R. I. Ristic, D. B. Sheen, and J. N. Sherwood. 2001. The bulk crystallization of $\alpha$-lactose monohydrate from aqueous solution. J. Pharm. Sci. 90:823-832.

Wong, S. Y., R. K. Bund, R. K. Connelly, and R. W. Hartel. 2012. Designing a lactose crystallization process based on dynamic metastable limit. J. Food Eng. 111:642-654.

Yucel, U., and J. N. Coupland. 2011. Ultrasonic characterization of lactose crystallization in gelatin gels. J. Food Sci. 76:E48-E54.

Zisu, B., M. Sciberras, V. Jayasena, M. Weeks, M. Palmer, and T. D. Dincer. 2014. Sonocrystallisation of lactose in concentrated whey. Ultrason. Sonochem. 21:2117-2121. 